\section{Reliability of Soil Sampling Method to Assess Visible Biodegradable Mulch Fragments Remaining in the Field after Soil Incorporation}

\author{
Shuresh Ghimire ${ }^{1,4,9}$, Arnold M. Saxton ${ }^{2,5}$, Annette L. Wszelaki ${ }^{3,6}$, \\ Jenny C. Moore ${ }^{3,7}$, and Carol A. Miles ${ }^{1,8}$
}

ADDITIONAL INDEX WORDS. mulch tillage, mulch distribution, biodegradation standard, biodegradable plastic mulch

SUMMARY. Biodegradable mulches (BDMs) provide a unique advantage to growers in that they can be tilled into the soil after use, eliminating disposal costs that include time, labor, and equipment needs. Biodegradation of BDMs in the soil can be assessed by the presence of visible mulch fragments; although this is not a direct measure of biodegradation, it provides an initial estimation of mulch biodegradation. We carried out three field experiments to develop a protocol for quantifying BDM fragments in the soil after soil incorporation of mulch. Expt. 1 was done at Mount Vernon, WA, and Knoxville, TN, using five BDMs in four replications, including a polyethylene (PE) mulch reference treatment (three replications and at Mount Vernon only), and a 'Cinnamon Girl' pumpkin (Cucurbita pepo) test crop. At the end of the growing season, mulches were tilled into the soil to a depth of 6 inches and within 16 days, five soil samples were collected with a golf hole cutter ( 4 inches diameter and 6 inches deep). Fifty-nine percent of the PE mulch fragments were recovered from the reference treatment. Among the remaining treatments, there was a high plot-to-plot variation as to the percent of the BDM recovered ( $3 \%$ to $95 \%$ at Mount Vernon, $2 \%$ to $88 \%$ at Knoxville). To exclude the possibility of mulch degradation impacting mulch recovery, in Expts. 2 and 3 (at Mount Vernon only), one BDM was laid, then tilled into the soil and sampled using the same sampling core as in Expt. 1, but all in 1 day. In Expt. 2, 15 soil samples were collected per plot, which recovered $70 \%$ of the mulch, and in Expt. 3, the entire plot was sampled by collecting 128 soil samples per plot, which recovered $62 \%$ of the mulch. In summary, sampling with a relatively large core recovered less than $70 \%$ of tilled-in mulch, there was high variability between plots within each treatment because of uneven distribution of the mulch fragments in the plot, and even $\mathbf{5 0}$ samples per plot did not provide an accurate estimate of the amount of mulch remaining in the field. Thus, soil sampling with a large core was ineffective, and new sampling methods are needed to assess the amount of BDM remaining in the field after soil incorporation.

$\mathrm{P}$ E mulch has been used in agriculture for 60 years, and is considered effective and affordable; however, its use leads to waste and pollution. In $2011, \mathrm{PE}$ mulch was used on nearly 20 million hectares in China with its use projected to grow $7 \%$ or more annually, whereas in 2012 , an estimated 98,300 tons of PE mulch was used in North America (Liu et al., 2014; Markets and Markets, 2012). Whereas PE mulch controls weeds, conserves soil moisture, and increases overall crop yield and quality (Cowan et al., 2014), this technology contributes to environmental pollution ( $\mathrm{Liu}$ et al., 2014). Most PE mulch is removed from the field and disposed of in landfills, buried or burned on-site, or dumped in streams, rivers, or the ocean because used PE mulch is contaminated with soil and crop debris (up to $50 \%$ by weight) and not readily recyclable (Kasirajan and Ngouajio, 2012). Residual PE mulch is left in the field [estimated 5\% to $10 \%$ (L. Martin-Closas, personal communication)], where it negatively impacts soil structure, water quality, and crop growth, and can enter water systems, thereby disrupting the agricultural ecosystem and overall environment (Steinmetz et al., 2016). It is worth noting that over $80 \%$ of the plastic waste found in oceans originates from disposal on land (Li et al., 2016).

Biodegradable plastics are degradable plastic in which the degradation results from the action of naturally occurring microorganisms such as bacteria, fungi, and algae (ASTM International, 2011). Biodegradable plastic offers a potential solution to some of the issues associated with PE mulch; however, BDM users are concerned about the extent and rate of mulch biodegradation in the field after soil incorporation and impacts on soil health and the productivity of subsequent crops (Goldberger et al., 2015; Miles et al., 2009; Yamamoto-Tamura et al., 2015). Many studies have evaluated crop yield with BDM as well as mulch functionality and deterioration (loss of physical or mechanical strength, as observed through physical strength testing, microscopic imaging, or sizable macroscopic alteration of morphology) during the growing season (Anzalone et al., 2010; Cowan et al., 2014; Jenni et al., 2007; Kasirajan and Ngouajio, 2012; Li et al., 2014; Miles et al., 2012; Moreno et al., 2009; Ngouajio et al., 2008; Waterer, 2010; Wortman et al., 2016). Deterioration of BDM aboveground is driven by temperature, sunlight, moisture, mechanical stresses, and their interactions, and can affect biodegradation, which primarily occurs belowground (Hablot et al., 2014; Kijchavengkul et al., 2008; Lucas et al., 2008; Singh and Sharma, 2008). Biodegradation is the disintegration of materials by microorganisms or other biological means, producing carbon dioxide $\left(\mathrm{CO}_{2}\right)$ or methane $\left(\mathrm{CH}_{4}\right)$, water, and microbial biomass (Kyrikou and Briassoulis, 2007). In the field, the extent of

\begin{tabular}{llll}
\hline $\begin{array}{l}\text { Units } \\
\text { To convert U.S. to SI, } \\
\text { multiply by }\end{array}$ & U.S. unit & SI unit & $\begin{array}{l}\text { To convert SI to U.S., } \\
\text { multiply by }\end{array}$ \\
\hline 0.3048 & $\mathrm{ft}$ & $\mathrm{m}$ & 3.2808 \\
3.7854 & gal & $\mathrm{L}$ & 0.2642 \\
2.54 & inch(es) & $\mathrm{cm}$ & 0.3937 \\
25.4 & inch(es) & $\mathrm{mm}$ & 0.0394 \\
6.4516 & inch & $\mathrm{cm}^{2}$ & 0.1550 \\
0.4536 & $\mathrm{lb}$ & $\mathrm{kg}$ & 2.2046 \\
1.6093 & $\mathrm{mph}$ & $\mathrm{km} \cdot \mathrm{h}^{-1}$ & 0.6214 \\
28.3495 & $\mathrm{oz}$ & $\mathrm{g}$ & 0.0353 \\
0.9072 & ton $(\mathrm{s})$ & $\mathrm{Mg}$ & 1.1023 \\
$\left({ }^{\circ} \mathrm{F}-32\right) \div 1.8$ & ${ }^{\circ} \mathrm{F}$ & ${ }^{\circ} \mathrm{C}$ & $\left({ }^{\circ} \mathrm{C} \times 1.8\right)+32$ \\
& & &
\end{tabular}


biodegradation of soil-incorporated BDM can be assessed by the presence of visible mulch fragments in soil samples. This does not directly measure the degree of biodegradation, but does provide an estimation of the initial stage of mulch biodegradation.

Currently, there is no established field method to measure the amount of BDM remaining in the soil after incorporation, and the few studies that have attempted to make assessments have used somewhat similar methods. Calmon et al. (1999) buried a known surface area $(5 \times 20 \mathrm{~cm})$ and mass of 19 films made from polyhydrobutyrate hydroxyvalerate, polycaprolactone (PCL), PCL-starch, poly (lactic acid) (PLA), starch-PLA, cellophane, protein, PE, PE-starch, and paper, where each material represented a different level of biodegradability. Each sample was placed in a PE mesh $(0.5 \times 0.5 \mathrm{~cm})$ bag, and samples were placed in the soil at five different depths $(0-20 \mathrm{~cm})$ at $45^{\circ}$ angle to enhance water drainage. Biodegradation was determined by measuring the mass of recovered samples (after cleaning) and the area (image analysis, method not specified) at $4,8,12,16,20$, and 24 months after burial. Results indicated that the

\footnotetext{
This article is based upon a work that is supported by the National Institute of Food and Agriculture (NIFA), U.S. Department of Agriculture (USDA) Specialty Crop Research Initiative, under award number 2014-51181-22382, and NIFA Hatch project 1008680. Any opinions, findings, conclusions, or recommendations expressed in this article are those of the authors and do not necessarily reflect the view of the USDA.

We appreciate the technical assistance by Ed Scheenstra, Danielle Crow, and Carolyn Klismith at Washington State University (WSU), and BJ DeLozier and Cody Fust at University of Tennessee. We thank Debra Inglis, Jeremy Cowan, and Markus Flury (WSU) for thorough review of the manuscript.

${ }^{1}$ Department of Horticulture, Washington State University, Northwestern Washington Research and Extension Center, 16650 State Route 536, Mount Vernon, WA 98273

${ }^{2}$ Department of Animal Science, University of Tennessee, 2506 River Drive, Knoxville, TN 37996

${ }^{3}$ Department of Plant Sciences, University of Tennessee, 2431 Joe Johnson Drive, Knoxville, TN 37996

${ }^{4} \mathrm{PhD}$ Candidate

${ }^{5}$ Professor and Statistician

${ }^{6}$ Associate Professor and Vegetable Horticulturist

${ }^{7}$ Research Specialist and Horticulturist

${ }^{8}$ Professor and Horticulturist

${ }^{9}$ Corresponding author. E-mail: shuresh.ghimire@ wsu.edu.
}

doi: 10.21273/HORTTECH03821-17 mass of PLA films in some samples increased up to $160 \%$ after 20 months because of high adherence of soil particles and mycelium on fragments even after cleaning, whereas image analysis of these same samples showed that the surface area decreased. The authors concluded that image analysis was more robust compared with mass measurements for assessing biodegradation in the field. Although this study included a positive control treatment (PE), the mulches were not exposed to field conditions within a cropping system before burial, nor were they incorporated into the soil using typical tillage practices as they would when used on a farm.

Li et al. (2014) also used mesh bags to evaluate biodegradation of four BDMs in three climatically distinct locations of the United States (Knoxville, TN; Lubbock, TX; Mount Vernon, WA) by measuring loss of mulch surface area. At all three locations, the authors found that after 24 months of burial, there was no decrease in the surface area of spunbond PLA [experimental nonwoven PLA (feedstock from NatureWorks, Blair, $\mathrm{NE}$ )], and the average surface area loss of two commercial BDMs [BioAgri (BioBag Americas, Palm Harbor, FL) and BioTelo Agri (Dubois Agrinovation, Waterford, ON, Canada)] was $52 \%$ at Knoxville, 98\% at Lubbock, and $6 \%$ at Mount Vernon. The biodegradability of the BDMs at all sites may have been reduced by the lack of subsequent soil tillage and the protection provided by the mesh bags. To address these two issues, Cowan et al. (2013) tilled three BDMs into the soil following a broccoli (Brassica oleracea var. italica) crop at Mount Vernon, WA, and 13 months after incorporation, randomly sampled the soil to a 6inch depth with a large soil core (golf hole cutter, 4 inches diameter). The authors bulked three soil samples per plot, and extracted the mulch through a wet sieve $(1.18 \mathrm{~mm})$ process. Mulch fragments were placed on a glass plate, photographed (EOS Digital Rebel XT; Canon USA, Lake Success, NY), and the surface area was calculated using image-processing software (Image); National Institutes of Health, Bethesda, MD) (Rasband, 1997). The authors calculated percent loss of surface area relative to that of the total soil sample, and found that surface area of spunbond PLA did not decrease whereas surface area of BioAgri mulch had decreased $60 \%$, and no fragments of Crown 1 mulch [currently marketed as Naturecycle (Custom Bioplastics, Burlington, WA)] were found. In a similar study, Wortman et al. (2016) grew cucumber (Cucumis sativus) on four experimental biofabrics [all spunbond nonwoven PLAs, but with different thickness and color (3M Co., Saint Paul, MN)], incorporated the mulch following the final cucumber harvest, collected soil samples with the same-sized soil core as Cowan et al. (2013) 9 months after incorporation, and measured the mass of recovered mulch fragments. Mulch recovery ranged from $5 \%$ to $55 \%$, which was in contrast with the results of Cowan et al. (2013) and Li et al. (2014) where $125 \%$ and $100 \%$ of the initial amount of spunbond PLA were recovered 13 and 24 months after soil incorporation, respectively. This difference in mulch recovery could have been related to different spunbond PLA formulations used in the different studies, but also could be due to inaccuracy of the soil sampling method. Moreno et al. (2014) reported a method to determine the amount of residual mulch remaining at the end of the season using image analysis, but that study did not incorporate the mulch into the soil; mulch was measured on the soil surface only.

Organic and other growers concerned about environmental sustainability frequently are interested in knowing if $\mathrm{BDM}$ is indeed biodegrading fully after soil incorporation. Although laboratory tests can assess the potential of a mulch product to biodegrade under certain conditions (ASTM International, 2012), results may vary widely under field conditions as demonstrated by the studies cited previously. Because sampling errors often have been much greater than analytical errors for general soil sampling studies in the past, developing reliable soil sampling methods is essential (Webster and Oliver, 1990). Random soil sampling is suitable only in a highly homogenous field. A reliable and efficient soil sampling protocol is needed that enables growers and agricultural professionals to estimate mulch biodegradation after soil incorporation.

The specific objectives of this study were to l) compare three methods (graph paper, image, and weight) 
to measure the amount of mulch recovered in soil samples; 2 ) determine the distribution of mulch fragments in the plot after soil incorporation; and 3) calculate the number of soil samples needed per unit area to assess the amount of mulch remaining in the soil.

\section{Materials and methods}

ExPERIMENTAL SITES. This study included three field experiments (details below by experiment). Expt. 1 was carried out in 2015 at two climatically and geographically diverse locations: the Washington State University, Northwestern Washington Research and Extension Center in Mount Vernon, WA, with a cool, humid climate and Skagit silt loam soil [U.S. Department of Agriculture (USDA), 1960]; and the University of Tennessee, East Tennessee Research and Education Center in Knoxville, TN, with a hot, humid climate and Shady loam soil (USDA, 2006). Expts. 2 and 3 were carried out in 2016 only at Mount Vernon.

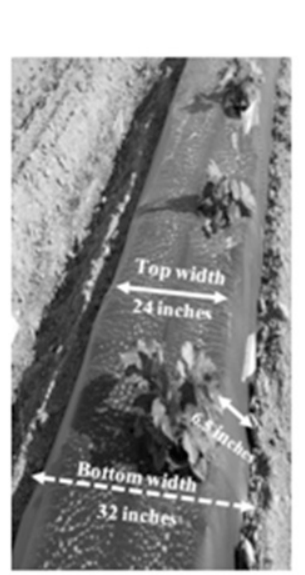

A

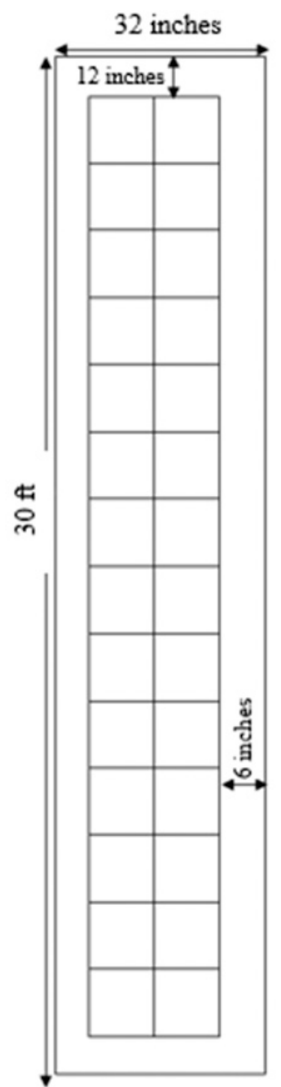

B
C

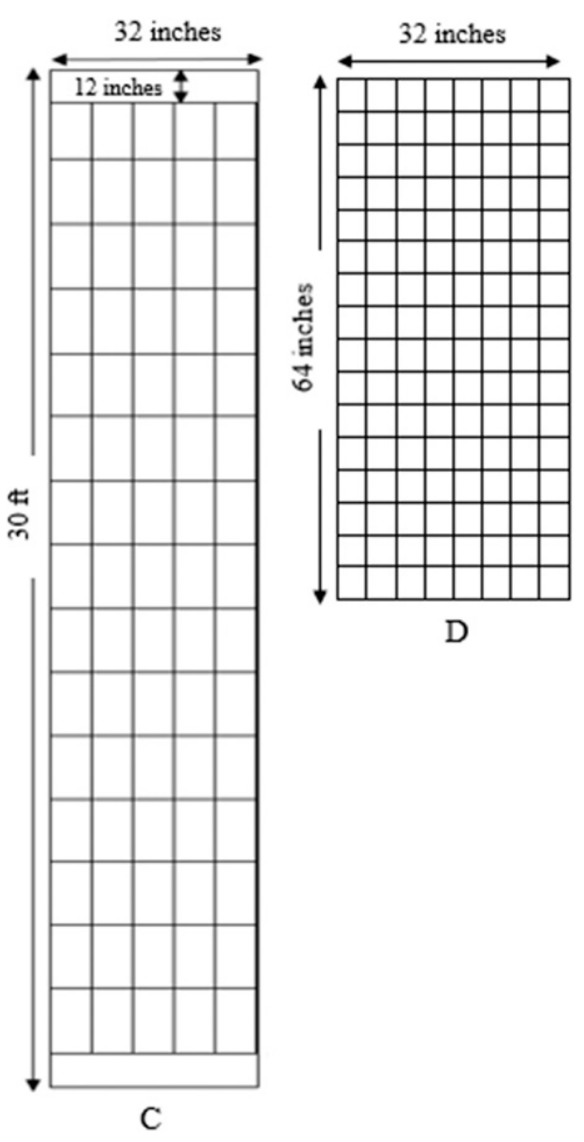

Plot establishment, tillage, AND SOIL CORE SAMPLING. In all three experiments, raised beds (6-7 inches high and 32 inches wide) were formed (Fig. 1A), and the mulch was laid by machine (model 2600 Bed Shaper; Rain-Flo Irrigation, East Pearl, PA). Plot size was 32 inches wide $\times 30 \mathrm{ft}$ long for Expts. 1 and 2, and 32 inches wide $\times 64$ inches long for Expt. 3. In Expt. 1, plots were tilled at the end of the growing season (4 months after mulch laying), and in Expts. 2 and 3, plots were tilled on the same day of mulch laying to avoid any mulch degradation. The plots were tilled with a rototiller [tiller 80 inches wide and 8 inches deep, power-take-off operating speed of $540 \mathrm{rpm}$, forward operating speed of $1.5 \mathrm{mph}$ (Terranova; Maschio Gaspardo North America, East DeWitt, IA)]. Rototilling was done twice to incorporate mulch, once in each direction parallel to the plots to minimize dragging of the mulch fragments from their initial placement, with the rototiller centered on the plot. PE

Fig. 1. A figure of a raised mulched bed (A), sampling grids for mulch recovery in Expts. 1 (B), 2 (C), and 3 (D) for three soil sampling experiments at Mount Vernon, WA, and Knoxville, TN, in 2015 and 2016; the length of the grid illustration for Expt. 3 is not to scale; 1 inch $=2.54 \mathrm{~cm}, 1 \mathrm{ft}=0.3048 \mathrm{~m}$. mulch (only in Expt. 1) was not easily cut into pieces by the tillage equipment and some large fragments were wrapped around the tiller blades and dragged to the end of the plot, unlike BDMs, which appeared evenly cut into small pieces. At the end of each plot, the rototiller was lifted, and mulch fragments and soil adhering to the blades were removed and redistributed randomly over the respective plot area and buried up to 6 inches deep with a shovel so that all mulch was incorporated into the plots. This type of rototiller is commonly used by farmers to incorporate mulch and crop debris into the soil and to prepare the soil for planting a winter cover crop. Mulch samples in all three experiments were collected to a 6-inch depth with a large soil core (golf cup cutter, 4 inches diameter). Although the length of tiller tines was 8 inches, we observed that tillage depth was up to 6 inches and minimal mulch fragments occurred below 6-inch depth. Previous studies that tested soil sampling as a means of measuring presence of mulch in the soil after incorporation have also used a large soil core with the same dimensions (Cowan et al., 2013; Wortman et al., 2016). The surface area of the core $\left(\pi r^{2}\right)$ provided a theoretical mulch area of 12.57 inch $^{2}$ per core.

EXPERIMENT 1. Treatments included five BDMs [BioAgri, Experimental PLA/polyhydroxyalkanoates (PHA), Naturecycle, Organix, and WeedGuardPlus] and black PE mulch as a reference control (Mount Vernon only) (Table 1). The treatments were replicated four times, except the $\mathrm{PE}$ reference plot, which was replicated three times. All mulches were laid on 26 May 2015 at Mount Vernon, and 28-29 May 2015 at Knoxville, and 'Cinnamon Girl' pumpkin was grown on the mulch at both locations. The growth habit of this pumpkin is fairly compact and vines tend to stay on the mulched bed. The effects of abrasive stem and leaf hairs and relatively heavy fruit $(3-5 \mathrm{lb})$ of this variety on the deterioration of the mulch was investigated in another paper ( $S$. Ghimire, A.L. Wszelaki, J.C. Moore, D.A. Inglis, and C. Miles, unpublished data) and is outside the scope of this experiment. After pumpkin harvest, mulches were tilled into the soil to a depth of $\approx 6$ inches on 28 Sept. 2015 
Table 1. Mulch treatments, manufacturers, and percent bio-based content (provided by manufacturers) for three soil sampling experiments at Mount Vernon, WA, and Knoxville, TN, in 2015 and 2016.

\begin{tabular}{|c|c|c|c|}
\hline & Treatment & Manufacturer & Bio-based (\%) \\
\hline \multirow[t]{6}{*}{ Expt. 1} & BioAgri & BioBag Americas, Dunedin, FL & $20-25$ \\
\hline & Experimental PLA/PHA ${ }^{\mathrm{z}}$ & Experimental film ${ }^{\mathrm{z}}$ & 86 \\
\hline & Naturecycle & Custom Bioplastics, Burlington, WA & $\geq 20$ \\
\hline & Organix & Organix Solutions, Maple Grove, MN & 10 \\
\hline & Polyethylene (reference) ${ }^{\mathrm{y}}$ & Filmtech, Allentown, PA & $<1$ \\
\hline & WeedGuardPlus & Sunshine Paper Co., Aurora, CO & 100 \\
\hline
\end{tabular}

${ }^{\mathrm{z}}$ Poly (lactic acid)/polyhydroxyalkanoates. Not available in the market; prepared for this study by Metabolix, Cambridge, MA.

${ }^{y}$ Polyethylene (reference) treatment was included only at Mount Vernon test site.

at Mount Vernon and on 14 Oct. 2015 at Knoxville.

Five soil core samples were collected from each plot randomly (using Excel random number generator) within $16 \mathrm{~d}$ of tillage $(9$ Oct. 2015 at Mount Vernon and 30 Oct. 2015 at Knoxville). A sampling grid of two columns $\times 14$ rows was centered on the plot such that 12 inches at each end and 6 inches on each side of the plot were not included in the sampling grid (Fig. 1B). Each sampling cell was $24 \times 10$ inches. Five samples were collected from the center of randomly selected cells in each plot and bulked. These samples represented $0.6 \%$ of the soil in the plot (based on volume). Mulch fragments were extracted, and the area of the fragments was measured using three methods (graph paper, image, and weight) described below. For the extraction of mulch fragments, the soil samples collected from mulch film treatments were placed in a $4-\mathrm{L}$ container, water was added, and the sample was gently hand stirred to loosen clumps, then the sample was poured through a $1.18-\mathrm{mm}$ sieve (No. 16; Dual Manufacturing Co., Chicago, IL) while adding water from a garden hose connected to a tap. We considered this sieve size as the smallest practical size to screen field soil and not lose visible mulch fragments. Mulch film fragments trapped on the sieve were extracted with forceps and then placed in a container with water to further remove soil. All mulch fragments were gently blotted dry, then air-dried $\left(23^{\circ} \mathrm{C}\right)$ for $1 \mathrm{~h}$. This method was not suitable for the recovery of paper mulch as water may cause the paper mulch to break into very small $(<1.18 \mathrm{~mm})$ pieces. Instead, soil samples for the paper mulch treatment (Expt. 1 only) were crumbled gently by hand, and then screened through the $1.18-\mathrm{mm}$ sieve, and mulch fragments were removed with forceps and then brushed gently to remove the soil. The total amount of mulch fragments recovered from each sample was measured using three methods: graph paper, image, and weight. The three mulch area measurement methods were then compared for accuracy, and the weight method was then used to compare treatments. Mixed model analysis of variance (version 9.4; SAS Institute, Cary, NC) produced least squares means, which were separated using Fisher's least significant difference at the $5 \%$ significance level.

EXPERIMENT 2. One mulch product, Experimental PLA/PHA, was machine laid on 17 Mar. 2016 at Mount Vernon and then immediately tilled into the soil to avoid any deterioration before soil sampling. Experimental PLA/PHA was chosen for Expts. 2 and 3 because its mechanical properties (density and percent elongation) are comparable to commercially available BDMs (Hayes et al., 2017), and detailed information regarding mulch ingredients (polymers, plasticizers, fillers, and other additives) were available for mulch degradation studies (however, this is beyond the scope of the current study). A sampling grid of five columns by 15 rows was centered on the plot such that the entire width of the mulched plot was included, but 12 inches at each end of each plot was not included in the grid. The size of each sampling cell was $22.4 \times$ 6.4 inches (Fig. 1C). The plot was divided into thirds lengthwise, and the samples were collected from the center of each cell. In each third of the plot, no row or column was sampled twice, and every row in the plot was sampled (Latin square sampling design). Fifteen soil samples were collected from each plot, and the soil samples were not bulked. These samples represented $1.7 \%$ of the soil in the plot. The experiment included four replicate plots, for a total of 60 soil samples. Whereas mulch area was measured using three methods (graph paper, image, and weight), only the weight method was used for response surface analysis (SAS version 9.4) to test for mulch fragment differences across rows or columns after soil incorporation. The weight method was used because it was found to be the most accurate measure of mulch area among the three methods tested (details below in the results and discussion section).

EXPERIMENT 3. One mulch product (Experimental PLA/PHA) was machine laid on 12 May 2016 at Mount Vernon and tilled down immediately to avoid deterioration before sampling. A soil-sampling grid of eight columns $\times 16$ rows covered the entire mulched plot (64 inches long and 32 inches wide) (Fig. 1D). The dimension of each sampling cell was $4 \times 4$ inches to match the diameter of the soil core, which was 4 inches. Soil cores were collected from every sampling cell (128 soil cores per plot) such that the entire plot was sampled. These samples represented $79 \%$ of the soil in the plot. The study included three replicates (384 soil cores). The soil samples were not bulked. Mulch area was measured using three methods (graph paper, image, and weight), but only the weight method was used for simulating sample sizes. The simulation took 100 random subsets of various sizes from each replicate, and mulch recovery was plotted to determine the number of soil core samples required to accurately estimate the amount of mulch remaining in the field after soil incorporation. Simulation generates a large number of samples based on the characteristics 
of the population from which the simulated samples are drawn.

GraPH PAPER. Mulch fragments from each soil sample were placed on a piece of graph paper as close to one another as possible without touching. The area covered by the mulch was calculated by multiplying length and width, which also included blank spaces between mulch fragments.

IMAGE CAPTURE AND ANALYSIS. The total surface area of the mulch collected from each soil sample was measured using an image processing software (ImageJ) using the method described by Cowan et al. (2013). Mulch fragments were spread without touching each other over a plain white background. A ruler was put on one side and was included in the photo. Mulch fragments were photographed with a digital single 6.224.8-mm lens camera (PowerShot A3100IS; Canon, Tokyo, Japan). Using the image processing software, the scale for each image was set by drawing a line between two points at least $5 \mathrm{~cm}$ apart. The image was converted to black and white such that the mulch fragments were black against a white background. Then the software calculated the total area of mulch fragments in each soil sample.

WEIGHT. After the other two measurements were completed, the total weight (grams) of the mulch fragments in each sample was recorded. Then from each sample, 10 relatively intact fragments were selected and each was cut into a rectangle. The area and weight of each rectangle were measured, and the weight per unit area was calculated. Total area of mulch for each soil sample was then calculated as

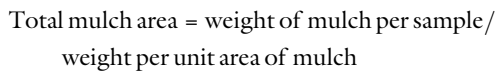

To control the accuracy of the weight method, actual mulch area and weight were measured. For this, 40 mulch pieces were cut into rectangles, length and width of each rectangle were measured, and each piece was weighed. Regression of actual mulch area and weight provided the relationship between mulch weight and mulch area.

STATISTICAL ANALYSIS. Area of the mulch fragments obtained through the three mulch area measurement methods (graph paper, image, and weight) was compared to determine the degree of agreement among these methods. Regressions of mulch area obtained with graph paper and image methods were run using the weight method as the independent variable (SAS version 9.4). Correction factors for graph and image methods were obtained by backsolving the regression equations.

\section{Results and discussion}

Mulch area measurement METHODS COMPARISON. Regression analysis showed a strong positive correlation between the mulch area measured using the weight method and the graph paper method $\left(R^{2}=\right.$ 0.97), and between the weight method and the image method $\left(R^{2}\right.$ $=0.98)$ (Fig. 2). Slopes for the graph paper and image methods differed from $1[1.15$ and 0.84 , respectively $(P<0.001)]$, indicating the methods were not in agreement with the weight method. The graph paper measurement method overestimated the mulch area, as expected, because the blank spaces between mulch fragments were included. The blank spaces between mulch fragments were about two times greater than the area lost because of folding and wrinkling. The mulch area obtained through image method was lower than the area obtained with the other two measurements. This result is very likely due to folding and wrinkling of the mulch fragments measured with the image method. A separate regression analysis showed a strong positive correlation between the mulch weight and its actual area $\left(R^{2}=\right.$ 0.99 ), and the intercept was not significantly different from 0 (intercept $=0.0009, P=0.08)($ Fig. 2). These results indicate that the weight method was the most accurate for measuring mulch area in this study. In addition, the mulch area in the weight method was not augmented because of empty spaces introduced between fragments or lost because of folds and wrinkles.

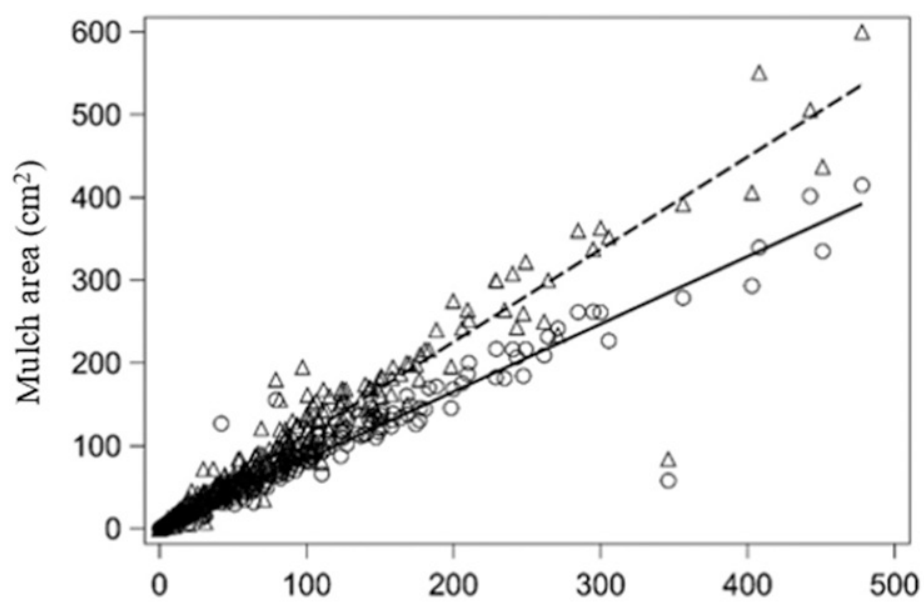

Mulch area calculated by the weight method $\left(\mathrm{cm}^{2}\right)$

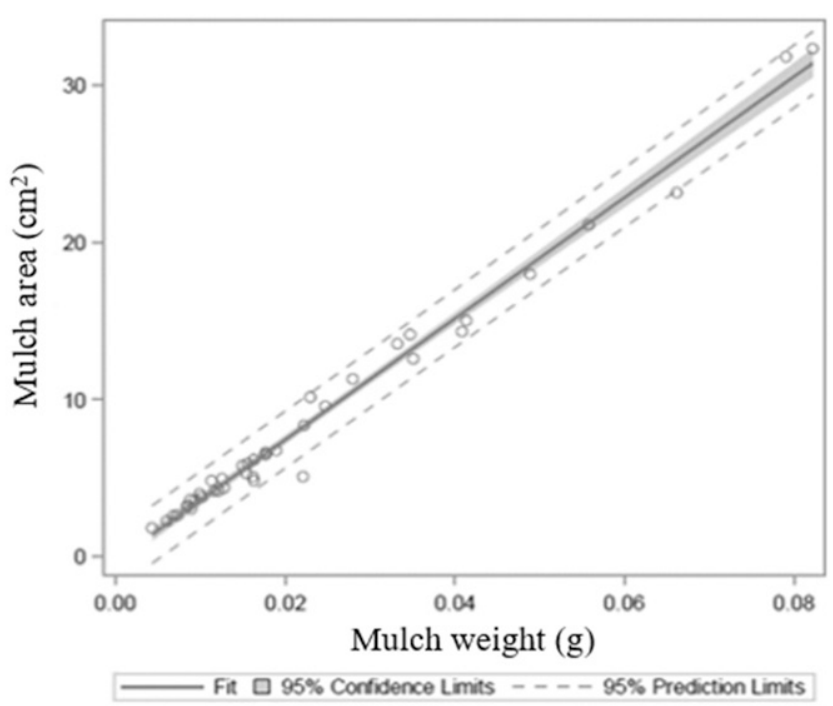

Fig. 2. Regression analysis between the mulch areas obtained from the graph paper and image methods as compared with the weight method (left), and regression of weight of mulch and actual mulch area (right) in three soil sampling experiments at Mount Vernon, WA, and Knoxville, TN, in 2015 and 2016; $1 \mathrm{~cm}^{2}=0.1550$ inch $^{2}, 1 \mathrm{~g}=0.0353 \mathrm{oz}$. 
The previously mentioned regression slopes can be used to correct the mulch area when using the graph paper and image methods:

$$
\begin{aligned}
& \text { Mulch area }=0.868 \\
& \times \text { area from graph paper method }
\end{aligned}
$$

Mulch area $=1.189$

$\times$ area from image method

Because the weight method was found to be most accurate, it was used for all other results presented.

SAMPLING Design. In Expt. 1, the mean \pm SE of the mulch fragments recovered from the three PE reference plots was $59 \% \pm 11.8 \%$ (range $44 \%$ to $83 \%$ ) (Table 2 ). The average percent recovery for the various BDM treatments ranged from $13 \%$ to $54 \%$ with se from $2.3 \%$ to $17.3 \%$ at Mount Vernon, and $0 \%$ to $72 \%$ with SE from $0 \%$ to $15.9 \%$ at Knoxville. Differences between the two sites in the amount of mulch recovered was likely due to greater weathering of mulches at Knoxville compared with Mount Vernon as reflected by the percent soil exposure in the mulched plots during the growing season, which was about three times higher (on average for all the mulches) at Knoxville than at Mount Vernon (S. Ghimire, A.L. Wszelaki, J.C. Moore, D.A. Inglis, and C. Miles, unpublished data). There are many factors involved in the rate of biodegradation seen at a specific site, such as temperature, soil $\mathrm{pH}$, water content, crop grown, and microbiota (Kyrikou and Briassoulis,
2007). One of the biggest differences between the two sites was that WeedGuardPlus mulch was essentially deteriorated before soil incorporation at Knoxville, whereas at Mount Vernon, aboveground WeedGuardPlus was almost entirely intact before soil incorporation. Other studies using paper mulches similar to WeedGuardPlus have reported a pattern of rapid breakdown similar to what was observed in Knoxville in the current study (Schonbeck, 1999; Shogren, 2000; Weber, 2003).

At both locations in Expt. 1, there was a high plot-to-plot variation in the amount of mulch recovered (3\% to $95 \%$ at Mount Vernon and $2 \%$ to $88 \%$ at Knoxville), and the variation was highest for BioAgri, Organix, and Experimental PLA/ PHA (Table 2). In contrast, plot-toplot variation in the amount of mulch recovered was relatively low for Naturecycle and WeedGuardPlus at both locations. Variation in the recovery rate was higher when more mulch was present before soil tillage.

In Expts. 2 and 3, 70\% and 62\% of the mulch was recovered (based on surface area of the soil core), respectively, from plots where a nonweathered BDM was tilled in and then sampled immediately after soil incorporation of the mulch. More mulch was found toward the sides of the plots compared with the center as expected because 29\% more mulch was present at the edges than at the center because of the angle of the edges of the bed (Fig. lA). It is reasonable that the distribution of the mulch fragments in the field would be more uniform if both tillage passes were perpendicular to each other. But in the current study, both passes were parallel to the plot and in opposite direction to minimize the dragging of the mulch fragments and reduce contamination between adjacent plots, as well as to conserve all the mulch fragments in the plot, which was the sampling area. There was a large sample-to-sample variation in the amount of mulch recovered [response surface method; this method uses row and column values to see curvature effects (any peaks or valleys in the distribution); $R^{2}=0.19$ for Expt. 2 and $R^{2}=0.05$ for Expt. 3] (Fig. 3). In Expt. 2, the distribution of the mulch fragments did not differ in the rows $(P=0.89)$, but mulch distribution was more concentrated toward the outside columns $(P=$ $0.03)$. In Expt. 3, the distribution of the mulch fragments differed both among the rows $(P=0.005)$ and the columns $(P=0.01)$. These results suggest that the distribution of the mulch fragments in the plot after soil incorporation was uneven. This uneven distribution could have been caused by many factors, such as the settings and types of equipment used for incorporation of the mulch, or because there was more mulch at the edge of the plot because of the angle of the edges of the bed. Therefore, random sampling could not estimate

Table 2. Maximum, minimum, and average percent mulch recovery from the field after soil incorporation in Expt. 1 at Mount Vernon, WA, and Knoxville, TN, in 2015 . The mulches were recovered using core sampling [ $4 \times 6$ inches $(10.2 \times 15.2 \mathrm{~cm})$ ] and the mulch recovery measured using the weight method (total mulch area $=$ weight of mulch per sample/weight per unit

\begin{tabular}{|c|c|c|c|c|c|c|c|c|}
\hline \multirow[b]{3}{*}{ Treatment $^{\mathrm{z}}$} & \multicolumn{8}{|c|}{ Mulch recovery (\%) } \\
\hline & \multicolumn{4}{|c|}{ Mount Vernon, WA } & \multicolumn{4}{|c|}{ Knoxville, TN } \\
\hline & Maximum & Minimum & Avg & SE & Maximum & Minimum & Avg & $\overline{S E}$ \\
\hline Experimental PLA/PHA & 77 & 34 & 54 & 9.3 & 83 & 8 & 43 & 15.9 \\
\hline Naturecycle & 21 & 3 & 13 & 3.8 & 18 & 2 & 8 & 3.6 \\
\hline Organix & 75 & 36 & 53 & 9.3 & 88 & 50 & 72 & 8.7 \\
\hline Avg & 63.5 & 25.0 & 41.5 & 9.0 & 69.0 & 21.8 & 38.2 & 7.6 \\
\hline
\end{tabular}
area of mulch).

${ }^{\mathrm{z}}$ Treatments included five commercial mulch products [BioAgri (BioBag Americas), Naturecycle (Custom Bioplastics), Organix (Organix Solutions), polyethylene (Filmtech), and WeedGuardPlus (Sunshine Paper Co.)], and an experimental poly (lactic acid)/polyhydroxyalkanoates (PLA/PHA) product prepared for this study by Metabolix. The mention of trade names is not meant to endorse any products listed or detract from any products not listed.

${ }^{y}$ Polyethylene reference plot was not included at Knoxville test site.

${ }^{x}$ WeedGuardPlus was almost completely deteriorated before soil incorporation at Knoxville (S. Ghimire, A.L. Wszelaki, J.C. Moore, D.A. Inglis, and C. Miles, unpublished data). 

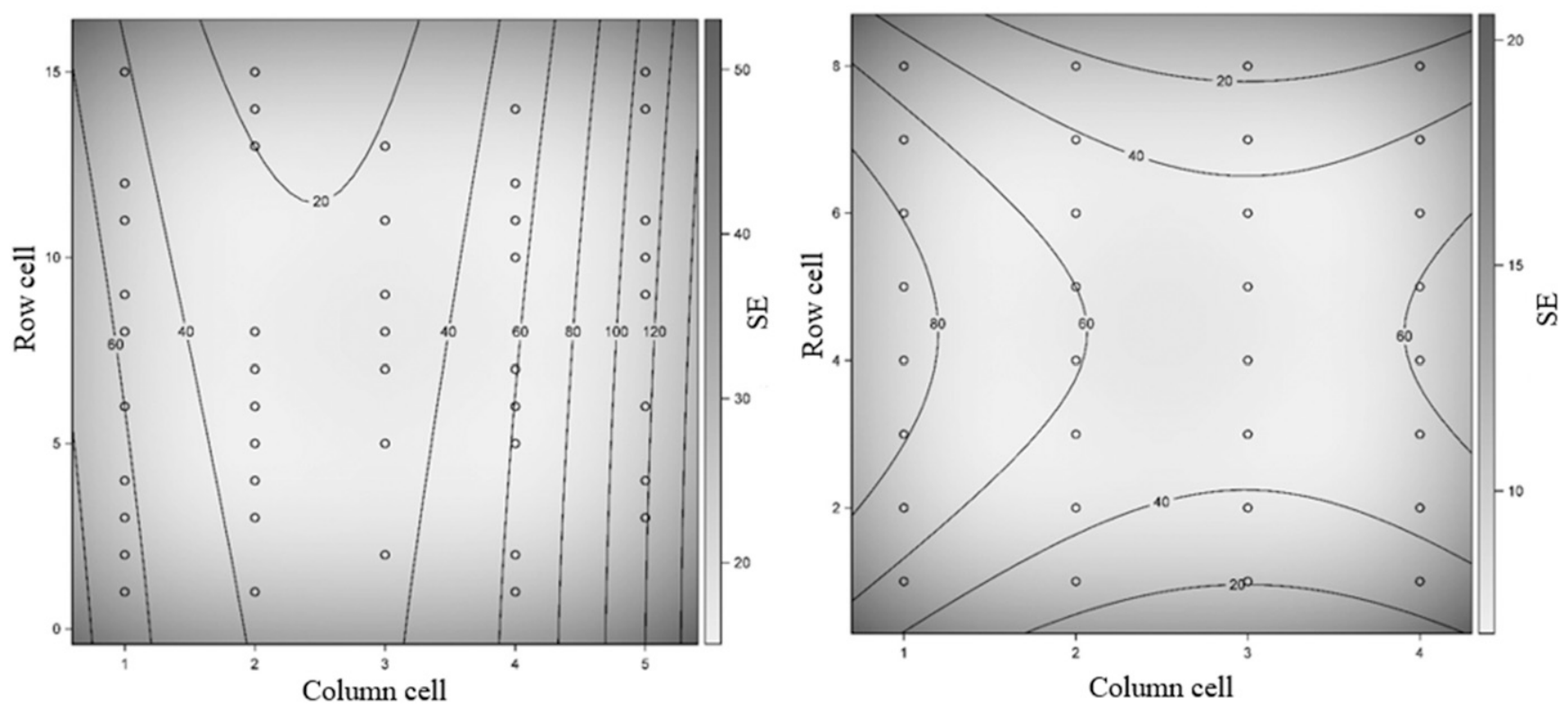

Fig. 3. Distribution of mulch fragments as shown by response contour lines in two soil sampling experiments at Mount Vernon, WA, and Knoxville, TN, in 2016; number along the lines indicate the area of mulch ( $\mathrm{cm}^{2}$ per sample) at respective areas in the plots after soil incorporation in Expts. 2 (left) and 3 (right); $1 \mathrm{~cm}^{2}=0.1550 \mathrm{inch}^{2}$.

the true amount of mulch remaining in the field.

To determine the minimum adequate number of soil core samples needed to accurately estimate the amount of mulch remaining in the field, a simulation approach was used. We calculated the SE for columns of data for various numbers of samples $(n)=10,20,50$, and 100 . The SES were $50,30,15$, and 9 at $n=10,20$, 50 , and 100 , respectively. The potential variation in the results from experiment to experiment was very high until $n>50$. For example, at $n=20$, the SE was 30 ; thus, when mean mulch sample recovery is $60 \%$, the true population mean falls within $0 \%$ to $120 \%$, which is not a reliable assessment of mulch remaining in the field. Furthermore, at $n=50$, the SE is 15 , and so for a sample mean of $60 \%$ recovery, the true population mean falls within $30 \%$ to $90 \%$. Therefore, even 50 samples per plot did not provide an accurate estimate of the amount of mulch remaining in the field (Fig. 4). Furthermore, taking 50 or more samples would not be practical for a grower because of time and resource constraints.

In this study, the width of the rototiller used to incorporate mulches into the soil was 80 inches, whereas the mulch width was 48 inches. Rototilling likely pushed mulch fragments outside the sample area as the rototiller width was 1.5 times greater than the bed width; therefore, some mulch fragments were not included in the sampling grid. It is also reasonable that all the BDMs with similar tensile strength would be equally impacted by the rototiller, and thus would have similar distribution in the plot. A comparative analysis of the mulch recovery among the mulch treatments could have been carried out even though mulch recovery was less than $70 \%$ if the sample-to-sample variation was acceptable. In this study, however, the high sample-to-sample variation resulted in unstable and nonreplicable results even when 50 soil core samples were assessed.

Biodegradation of BDM can be estimated in laboratory tests by measuring $\mathrm{CO}_{2}$ evolution (Krzan et al., 2006; Yabannavar and Bartha, 1994) and other methods (Eubeler et al., 2009; Lucas et al., 2008; Van der Zee, 2011). Solid-state nuclear magnetic resonance spectroscopy and thermochemolysis also have been used to measure degradation of BDMs in an on-farm composting system (Spaccini et al., 2016). However, these methods do not work well in applied agricultural field settings because of the complexity of soil composition (Briassoulis et al., 2015). This situation reiterates the need for reliable field sampling methods to estimate the biodegradation of BDMs after soil incorporation. Our results showed that distribution of mulch fragments in the field after incorporation is uneven. Therefore, future studies should use geostatistics to develop a sampling protocol.

Another important consideration when measuring the amount of mulch remaining in the soil is mulch particles that are too small to see. Although measuring mulch surface area loss in field studies can provide a benchmark measurement for the biodegradation potential of a mulch product, it does not take into account the possibility that microfragments, nanofragments, or both persist in the soil (Rillig, 2012; Steinmetz et al., 2016). Recent work has focused on developing methods to detect microplastics in environmental samples (Dümichen et al., 2015; Majewsky et al., 2016), and these techniques could possibly be helpful to more accurately determine the amounts of mulch remaining after soil incorporation. The ability to measure the amount of mulch remaining in the field is especially important for certified organic growers in the United States as $\mathrm{BDMs}$ are required to reach at least $90 \%$ biodegradation within 2 years of use, otherwise organic growers may be out of compliance with organic production rules (Miles et al., 2017; USDA, 2014). 


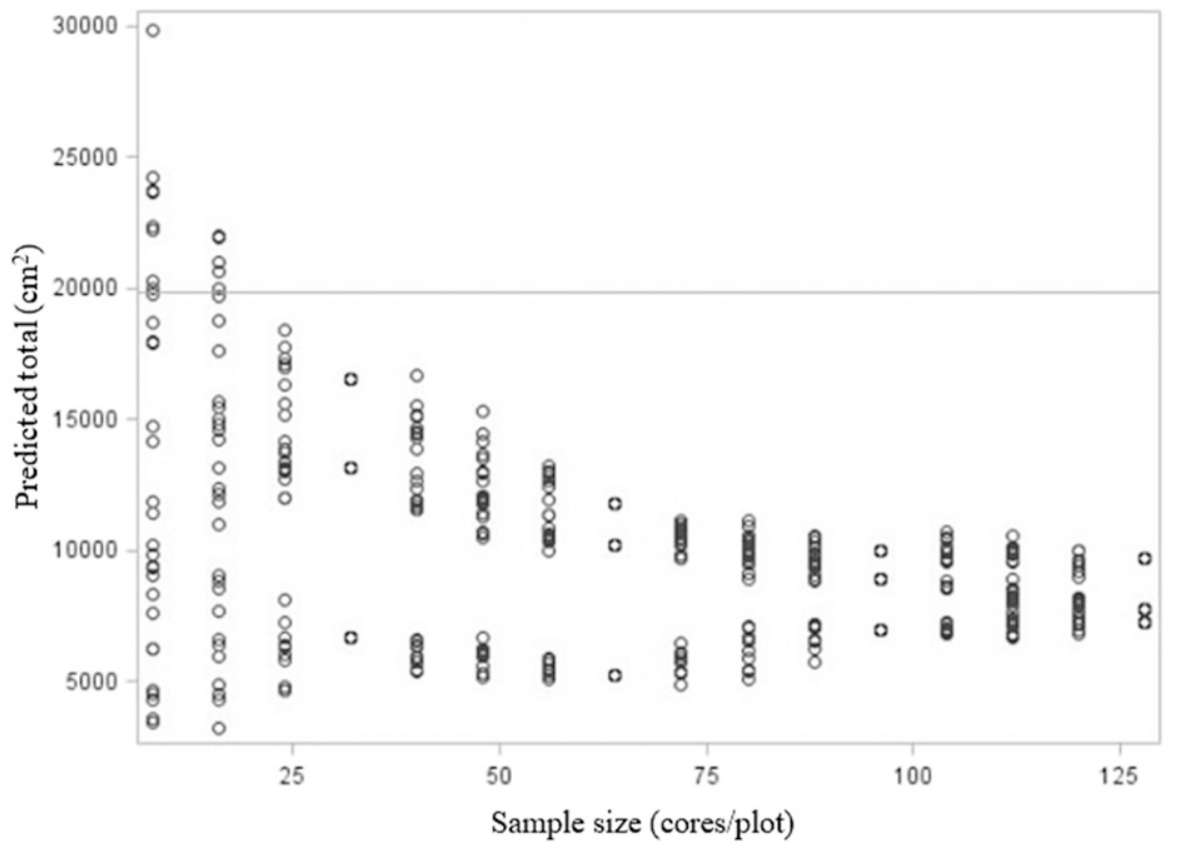

Fig. 4. Simulation of sample size (cores per plot) to find the minimum number of soil core samples required to provide an accurate measure of the amount of mulch remaining in the field after soil incorporation in Expt. 3 of a soil sampling study at Mount Vernon, WA, in 2016 . Horizontal line at $20,000 \mathrm{~cm}^{2}$ indicates the amount of mulch tilled in the plot. Highly spread data points with lower sample size indicate higher variability in the predicted total amount of mulch recovered. The variability decreased with increase in the sample size; $1 \mathrm{~cm}^{2}=0.1550 \mathrm{inch}^{2}$.

\section{Conclusions}

In the current study, we compared three different methods to measure the amount of mulch recovered in soil samples, we determined the distribution of mulch fragments in the field plot after tillage incorporation, and we determined the minimum number of soil samples needed to reasonably quantify the amount of mulch remaining in the field after soil incorporation. Among the three mulch area measurement methods tested, the weight method was the most accurate to measure the area of the recovered mulch fragments; however, cleaning the fragments thoroughly was critical for accuracy, and this method was extremely time-consuming. The graph paper method was quick but included subjective rating; this method can be used to estimate mulch area if mulch pieces are carefully placed as close together as possible. The image method can also be used, and although it is not as subjective, it does require a camera and computer to calculate mulch area. For both the graph paper and the image methods, it is necessary to smooth out the mulch fragments as much as possible before assessing their areas. In addition, a correction factor should be calculated for each unique situation by any researcher using a reasonable number of initial samples and then used for the rest of the samples. The results from this study indicate that when using a relatively large soil core, less than $70 \%$ of the mulch present after soil incorporation was recovered. In addition, there was high variability among samples in the amount of mulch recovered. The distribution of the mulch fragments after tillage incorporation was uneven, and more mulch was found toward the edges compared with the center of the bed. Even 50 samples per plot did not provide an accurate estimate of the amount of mulch remaining in the field. Thus, the soil core sampling method is not an accurate, reliable, or practical method to estimate the amount of mulch remaining in the field after soil incorporation, and new methods are needed.

\section{Literature cited}

Anzalone, A., A. Cirujeda, J. Aibar, G. Pardo, and C. Zaragoza. 2010. Effect of biodegradable mulch materials on weed control in processing tomatoes. Weed Technol. 24:369-377.
ASTM International. 2011. ASTM D883: International standard terminology relating to plastics. ASTM Intl., West Conshohocken, PA.

ASTM International. 2012. ASTM D598812: Standard test method for determining aerobic biodegradation of plastic materials in soil. ASTM Intl., West Conshohocken, PA.

Briassoulis, D., E. Babou, M. Hiskakis, and I. Kyrikou. 2015. Analysis of long-term degradation behaviour of polyethylene mulching films with pro-oxidants under real cultivation and soil burial conditions. Environ. Sci. Pollut. Res. 22:2584-2598.

Calmon, A., S. Guillaume, V. BellonMaurel, P. Feuilloley, and F. Silvestre. 1999. Evaluation of material biodegradability in real conditions - Development of a burial test and an analysis methodology based on numerical vision. J. Environ. Polym. Degrad. 7:157-166.

Cowan, J.S., D.A. Inglis, and C.A. Miles. 2013. Deterioration of three potentially biodegradable plastic mulches before and after soil incorporation in a broccoli field production system in northwestern Washington. HortTechnology 23:849858 .

Cowan, J.S., C.A. Miles, P.K. Andrews, and D.A. Inglis. 2014. Biodegradable mulch performed comparably to polyethylene in high tunnel tomato (Solanum lycopersicum L.) production. J. Sci. Food Agr. 94:1854-1864.

Dümichen, E., A. Barthel, U. Braun, C.G. Bannick, K. Brand, M. Jekel, and R. Senz. 2015. Analysis of polyethylene microplastics in environmental samples, using a thermal decomposition method. Water Res. 85:451-457.

Eubeler, J.P., S. Zok, M. Bernhard, and T.P. Knepper. 2009. Environmental biodegradation of synthetic polymers I. Test methodologies and procedures. Trends Analyt. Chem. 28:1057-1072.

Goldberger, J.R., R.E. Jones, C.A. Miles, R.W. Wallace, and D.A. Inglis. 2015. Barriers and bridges to the adoption of biodegradable plastic mulches for US specialty crop production. Renew. Agr. Food Syst. 30:143-153.

Hablot, E., S. Dharmalingam, D.G. Hayes, L.C. Wadsworth, C. Blazy, and R. Narayan. 2014. Effect of simulated weathering on physicochemical properties and inherent biodegradation of PLA/ PHA nonwoven mulches. J. Polym. Environ. 22:417-429.

Hayes, D., L. Wadsworth, H. Sintim, M. Flury, M. English, S. Schaeffer, and A. Saxton. 2017. Effect of diverse weathering conditions on the physicochemi- 
cal properties of biodegradable plastic mulches. Polym. Test. 62:454-467.

Jenni, S., D. Brault, and K.A. Stewart. 2007. Degradable mulch as an alternative for weed control in lettuce produced on organic soils. Acta Hort. 638:111-118.

Kasirajan, S. and M. Ngouajio. 2012. Polyethylene and biodegradable mulches for agricultural applications: A review. Agron. Sustain. Dev. 32:501-529.

Kijchavengkul, T., R. Auras, M. Rubino, M. Ngouajio, and R.T. Fernandez. 2008. Assessment of aliphatic-aromatic copolyester biodegradable mulch films. Part I: Field study. Chemosphere 71:942-953.

Krzan, A., S. Hemjinda, S. Miertus, A. Corti, and E. Chiellini. 2006. Standardization and certification in the area of environmentally degradable plastics. Polym. Degrad. Stabil. 91:2819-2833.

Kyrikou, I. and D. Briassoulis. 2007. Biodegradation of agricultural plastic films: A critical review. J. Polym. Environ. 15:125-150.

Li, C., J. Moore-Kucera, C. Miles, K. Leonas, J. Lee, A. Corbin, and D. Inglis. 2014. Degradation of potentially biodegradable plastic mulch films at three diverse U.S. locations. Agroecol. Sustain. Food Syst. 38:861-889.

Li, W.C., H.F. Tse, and L. Fok. 2016. Plastic waste in the marine environment: A review of sources, occurrence and effects. Sci. Total Environ. 566:333-349.

Liu, E.K., W.Q. He, and C.R. Yan. 2014. 'White revolution' to 'white pollution' Agricultural plastic film mulch in China. Environ. Res. Lett. 9:091001.

Lucas, N., C. Bienaime, C. Belloy, M. Queneudec, F. Silvestre, and J.E. NavaSaucedo. 2008. Polymer biodegradation: Mechanisms and estimation techniques A review. Chemosphere 73:429-442.

Majewsky, M., H. Bitter, E. Eiche, and H. Horn. 2016. Determination of microplastic polyethylene (PE) and polypropylene (PP) in environmental samples using thermal analysis (TGA-DSC). Sci. Total Environ. 568:507-511.

Markets and Markets. 2012. Agricultural films market by applications and polymers Global trends and forecasts to 2017. MarketsandMarkets Research Private, Maharashtra, India.

Miles, C., C. Beus, A. Corbin, R.W. Wallace, A.L. Wszelaki, H. Saez, T. Walters, K. Leonas, M. Brodhagen, D.G. Hayes, and D.A. Inglis. 2009. Research and extension priorities to ensure adaptaion of high tunnels and biodegradable plastic mulch in the United Sates. Proc. 35th Natl. Agr. Plastics Congr. p. 102-108.

Miles, C.A., L. DeVetter, S. Ghimire, and D.G. Hayes. 2017. Suitability of biodegradable plastic mulches for organic and sustainable agricultural production systems. HortScience 52:10-15.

Miles, C., R. Wallace, A. Wszelaki, J. Martin, J. Cowan, T. Walters, and D. Inglis. 2012. Deterioration of potentially biodegradable alternatives to black plastic mulch in three tomato production regions. HortScience 47:1270-1277.

Moreno, C., I. Mancebo, A.M. Tarquis, and M.M. Moreno. 2014. Univariate and multivariate analysis on processing tomato quality under different mulches. Sci. Agr. 71:114-119.

Moreno, M.M., A. Moreno, and I. Mancebo. 2009. Comparison of different mulch materials in a tomato (Solanum lycopersicum L.) crop. Span. J. Agr. Res. 7:454-464.

Ngouajio, M., R. Auras, R.T. Fernandez, M. Rubino, J.W. Counts, and T. Kijchavengkul. 2008. Field performance of aliphaticaromatic copolyester biodegradable mulch films in a fresh market tomato production system. HortTechnology 18:605-610.

Rasband, W.S. 1997. ImageJ. 28 Mar. 2017. <http://rsb.info.nih.gov/ij>.

Rillig, M.C. 2012. Microplastic in terrestrial ecosystems and the soil. Environ. Sci. Technol. 46:6453-6454.

Schonbeck, M.W. 1999. Weed suppression and labor costs associated with organic, plastic, and paper mulches in small-scale vegetable production. J. Sustain. Agr. 13:13-33.

Shogren, R.L. 2000. Biodegradable mulches from renewable resources. J. Sustain. Agr. 16:33-47.

Singh, B. and N. Sharma. 2008. Mechanistic implications of plastic degradation. Polym. Degrad. Stabil. 93:561-584.

Spaccini, R., D. Todisco, M. Drosos, A. Nebbioso, and A. Piccolo. 2016. Decomposition of bio-degradable plastic polymer in a real on-farm composting process. Chem. Biol. Technol. 3:1-12.
Steinmetz, Z., C. Wollmann, M. Schaefer, C. Buchmann, J. David, J. Troger, K. Munoz, O. Fror, and G.E. Schaumann. 2016. Plastic mulching in agriculture: Trading short-term agronomic benefits for long-term soil degradation. Sci. Total Environ. 550:690-705.

U.S. Department of Agriculture. 1960. Soil survey: Skagit County. 5 June 2017. <https://www.nrcs.usda.gov/Internet/ FSE_MANUSCRIPTS/washington/ skagitWA1960/skagitWA1960.pdf>.

U.S. Department of Agriculture. 2006. Soil survey of Knox County, Tennessee. 5 June 2017. <https://www.nrcs.usda.gov/ Internet/FSE_MANUSCRIPTS / tennessee/knoxTN2006/Knox_TN.pdf>.

U.S. Department of Agriculture. 2014. National organic standards (NOS) $\$ 205.601$ (b)(2)(i-ii) synthetic substances allowed for use in organic crop production. U.S. Dept. Agr., Washington, D.C.

Van der Zee, M. 2011. Analytical methods for monitoring biodegradation processes of environmentally degradable polymers, p. 263-281. In: A. Lendlein and A. Sisson (eds.). Handbook of biodegradable polymers. Wiley-VCH, Weinheim, Germany.

Waterer, D. 2010. Evaluation of biodegradable mulches for production of warm-season vegetable crops. Can. J. Plant Sci. 90:737-743.

Weber, C.A. 2003. Biodegradable mulch films for weed suppression in the establishment year of matted-row strawberries. HortTechnology 13:665-668.

Webster, R. and M.A. Oliver. 1990. Statistical methods in soil and land resource survey. Oxford Univ. Press, Oxford, UK.

Wortman, S.E., I. Kadoma, and M.D. Crandall. 2016. Biodegradable plastic and fabric mulch performance in field and high tunnel cucumber production. HortTechnology 26:148-155.

Yabannavar, A.V. and R. Bartha. 1994. Methods for assessment of biodegradability of plastic films in soil. Appl. Environ. Microbiol. 60:3608-3614.

Yamamoto-Tamura, K., S. Hiradate, T. Watanabe, M. Koitabashi, Y. SameshimaYamashita, T. Yarimizu, and H. Kitamoto. 2015. Contribution of soil esterase to biodegradation of aliphatic polyester agricultural mulch film in cultivated soils. AMB Express 51:1-8. 